\title{
A case of infantile Sweet's syndrome
}

\section{Monisha Devi Selvakumar, Bittanakurike Narasappa Raghavendra, Anjan Kumar Patra}

\author{
Department of Dermatology, MVJ Medical College and Research Hospital, Bangalore, India \\ Corresponding author: Dr. Monisha Devi Selvakumar, E-mail: monishadevi0507@gmail.com
}

\begin{abstract}
Sweet's syndrome is a dermal neutrophilic inflammatory dermatosis characterized by unrestricted neutrophil production with consequent infiltration of the skin and in some cases other organs. We report a 4 month old baby boy with multiple well-defined skin coloured to erythematous, edematous papules and plaques studded with sterile pustules along the periphery involving the entire body since 1 week with sparing of palms, soles and mucosae. Thick crusts were seen involving the entire scalp. Laboratory investigations and histopathology were suggestive of neutrophilic dermatoses (Sweet's syndrome).
\end{abstract}

Key words: Sweet's syndrome; Infant (4 month old); Dermal Neutrophilic dermatoses

\section{INTRODUCTION}

Sweet's syndrome (Acute Febrile Neutrophilic Dermatoses) is characterized by a constellation of acute onset of fever, neutrophilia, erythematous, and tender skin lesions that typically show an infiltrate of mature neutrophils in upper dermis, and the prompt improvement of both symptoms and lesions after initiation of treatment with systemic corticosteroids [1].

It presents in three clinical settings: 'classical' ('para-infectious') Sweet's syndrome, representing a hypersensitivity reaction preceding infection; paraneoplastic Sweet's syndrome (in children usually associated with acute myelogenous leukemia); and less frequently as an adverse drug reaction, sometimes in connection with certain underlying diseases (drug induced Sweet's syndrome) [2].

Sweet's syndrome is rarely diagnosed in children. We report a rare case of Sweet's syndrome in an infant.

\section{CASE REPORT}

A 4-month old baby boy was brought by his mother with complaints of history of moderate grade intermittent fever since 15 days, pus filled lesions on face, trunk, extremities and diffuse crusting on scalp since one week. The pus-filled lesions initially started on the nose and rapidly progressed over 3 days in number and size to involve the rest of the body. Mother also gave complaint of 3 episodes of non-blood tinged, non projectile vomiting one day back and excessive cry. On examination, the baby had a fever of $100 \mathrm{~F}$.

On cutaneous examination, multiple well-defined skin-coloured to erythematous papules and few plaques were seen involving the face, trunk, and extremities (Figs. la and lb), sparing the palms and soles. The plaques showed sterile pin-point pustules arranged along the periphery. Mild scaling was also seen on the papules and plaques. Scalp showed diffuse thick adherent crust (Fig. 2).

Laboratory investigations on the first day are shown in the table 1 below. It revealed leucocytosis with neutrophilia, raised C-Reactive protein and raised ESR. Biopsy revealed features suggestive of Sweet's syndrome.

Clinically, differential diagnoses of pustular psoriasis, Infantile seborrheic dermatitis with eczematisation, Atopic dermatitis, Impetigo with eczematisation and Sweet's syndrome were thought of and skin biopsy

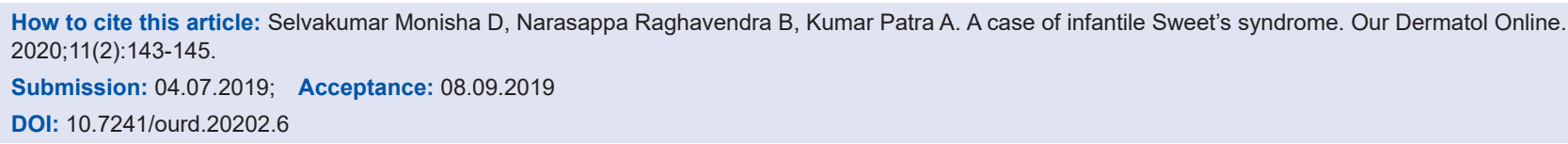


Table 1: Shows Leucocytosis (Neutrophilia), Raised Erythrocyte sedimentation rate, Raised Absolute neutrophil count and Positive C- reactive protein

\begin{tabular}{llc}
\hline No. & Laboratory investigation & Result \\
\hline 1. & Leucocytes (/micro Litre) & 37,300 \\
2. & Neutrophils (\%) & 62 \\
3. & Hemoglobin (grams/decilitre) & 8.6 \\
4. & Platelets (Lakh/cubic millimeter) & 5.4 \\
5. & Erythrocyte Sedimentation & 48 \\
& Rate (millimeter/1 ${ }^{\text {st }}$ hour) & \\
6. & Band forms & 12 (Metamyelocyte-4, Myelocyte-2) \\
7. & Peripheral smear & Normocytic normochromic anemia \\
& & with neutrophilic leucocytosis \\
8. & Absolute Lymphocyte & 7540 \\
& count (cells/micro Litre) & 23374 \\
9. & Absolute Neutrophil & Positive \\
& count (cells/micro Litre) & Negative \\
10. & C-Reactive Protein & \\
11. & ASLO titre &
\end{tabular}

was done. The child was then started on systemic antibiotics (Amoxicillin-clavulanic acid) and topical antibiotics.

Over the next 4 days, the papules and plaques increased in size and appeared edematous with scaling. New lesions started to appear on face and extremities. Fever spike of $100 \mathrm{~F}$ was seen. The child became irritable. However, feeding, bowel and bladder movements were normal.

The child was then started on intravenous Vancomycin and topical fluticasone-mupirocin ointment.

Biopsy revealed neutrophilic exocytosis in epidermis. Superficial dermis showed edema with dense inflammatory cell infiltrate composed chiefly of neutrophils. No features of leucocytoclastic vasculitis was seen (Fig. 3). All these features were suggestive of neutrophilic dermatoses - Sweet's syndrome.

The child was then started on systemic steroids (prednisolone at $\mathrm{lmg} / \mathrm{Kg}$ body weight) and topical fluticasone- mupirocin ointment was continued.

\section{DISCUSSION}

Sweet's syndrome, also known as acute febrile neutrophilic dermatosis, was originally described by Dr. Robert Douglas Sweet in 1964 [1].

Sweet's syndrome is relatively rare in pediatric age group. It occurs equally in male and female gender with a slight predominance in male gender among children less than three years of age [3].

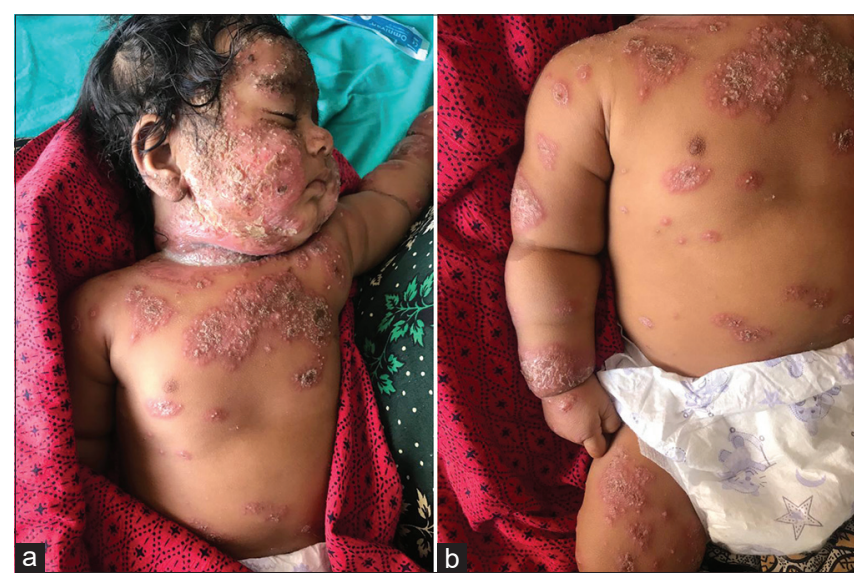

Figure 1: $(a$ and $b)$ Multiple papules and plaques with pustules, crusting and mild scaling.

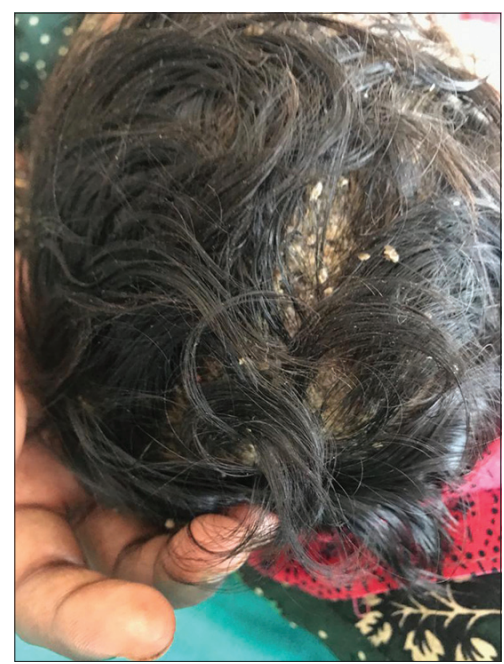

Figure 2: Diffuse crusting on scalp.

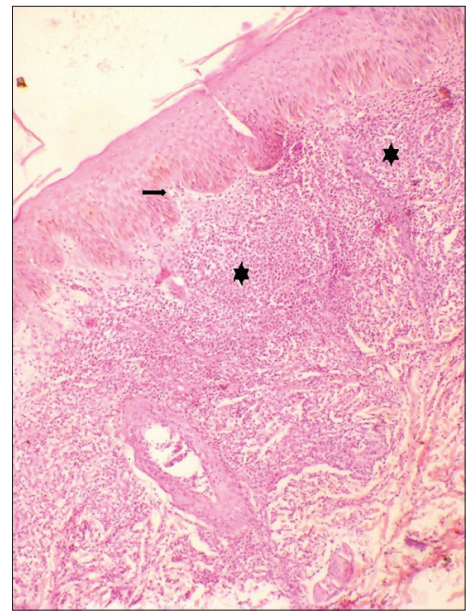

Figure 3: Histopatology showing acantosis, spongious, neutrophilic exocytosis and neutrophilic infiltrate in upper dermis.

$\rightarrow$ neutrophilic exocytosis

*neutrophilic infiltrate involving upper dermis

Sweet's syndrome can be classified as primary or secondary. Secondary Sweet's syndrome can be associated 
with inflammatory conditions including infections and autoimmune diseases, paraneoplastic or drug related [4].

Compared with adult disease, pediatric cases are less frequently associated with malignancy and are more likely postinfectious [5].

In pediatrics, up to $45 \%$ of idiopathic cases have been described after a transient gastrointestinal or respiratory infection, $30 \%$ cases were associated with chronic inflammatory conditions, and $25 \%$ of cases were paraneoplastic, where the greatest association was with acute myeloid leukemia, osteosarcoma, and myelodysplastic syndrome [2].

Mucocutaneous manifestations include acute eruption of tender erythematous papules or nodules and/ or plaques. Intense dermal edema can lead to pseudovesicular appearance. Other variants such as bullous, ulcerative and pustular lesions can be seen. Bullous or ulcerated lesions mimicking pyoderma gangrenosum more commonly found in malignancy associated Sweet's syndrome [6].

It is recommended that the first treatment of choice for Sweet's syndrome is systemic corticosteroids and this is generally effective. For refractory cases mostly occurring in malignancy-associated or drug-induced Sweet syndrome, potassium iodide and colchicine are employed as alternative first-line therapies and as second-line treatments indomethacin, cyclosporine or dapsone could be administered [7].

\section{CONCLUSION}

Sweet's syndrome is a relatively rare pediatric diagnosis. This condition is often mistaken for an infectious disease. Therefore a high index of suspicion is needed for its diagnosis. Along with the clinical manifestations, histopathological and laboratory parameters are required for its diagnosis. It is important to identify the underlying cause of Sweet's syndrome for adequate treatment. Patients should have a proper follow-up due to risk of recurrence.

\section{Consent}

The examination of the patient was conducted according to the Declaration of Helsinki principles.

\section{REFERENCES}

1. Cohen PR, Honigsmann H, Kurzrock R. Acute Febrile Neutrophilic Dermatosis(Sweet Syndrome); Chapter 32 in Fitzpatrick's Dermatology in General Medicine; $8^{\text {th }}$ edn(Vol 1). Mc Graw Hill Publisher; 2012.pp 362-71.

2. Makis A, Stavrou S, Chaliasos N, Zioga A, Vlahos AP, Gaitanis G, et al. Acute febrile neutrophilic dermatosis (Sweet's syndrome) in a child, associated with a rotavirus infection: a case report. J Med Case Rep. 2010;4:281.

3. Stevens GJ, Yutronic HJ, Pizarro OJ, Velozo PL. Sweet syndrome in pediatrics. A case report. Rev Chil Pediatr. 2018;89:511-5.

4. Spengane Z, Hlela C, Pillay K. Neonatal lupus erythematosus or Sweet syndrome?. JAAD Case Rep, 2018;4:780-3.

5. Sharma A, Rattan R, Shankar V, Tegta GR, Verma GK. Sweet's syndrome in a 1-year-old child. Indian J Paediatr Dermatol. 2015;16:29-31.

6. Panda S, Ghosh A. Neutrophilic Dermatoses; Chapter 34 in IADVL Textbook of Dermatology; $4^{\text {th }}$ edn (Vol 2). Bhalani Publishing House, Mumbai, India; 2015. Pp 1253-7.

7. Shinozuka J, Tomiyama H, Tanaka S, Tahara J, Awaguni H, Makino S, et al. Neonatal Sweet's syndrome associated with rectovestibular fistula with normal anus. Pediatr Rep. 2015;7:5858.

Copyright by Monisha Devi Selvakumar, et al. This is an open-access article distributed under the terms of the Creative Commons Attribution License, which permits unrestricted use, distribution, and reproduction in any medium, provided the original author and source are credited.

Source of Support: Nil, Conflict of Interest: None declared. 